\title{
Artigo/Article
}

\section{Leishmaniose tegumentar canina no município de Balneário Camboriú, Estado de Santa Catarina}

\author{
Canine tegumentar leishmaníasis in the town of Balneário Camboriú in the State of Santa Catarina
}

\author{
Afonso Heusser Júnior ${ }^{1}$, Valdomiro Bellato ${ }^{2}$, Antonio Pereira de Souza ${ }^{2}$, Anderson Barbosa de Moura ${ }^{2}$, \\ Amélia Aparecida Sartor ${ }^{2}$, Elizabeth Glória Oliveira Barbosa Santos ${ }^{3}$ e Valmir Laurentino Silva ${ }^{3}$
}

\begin{abstract}
RESUMO
Introdução: O aumento no número de casos de leishmaniose tegumentar americana no ano de 2005 foi em decorrência do surto ocorrido nos Municípios de Itapema e Balneário Camboriú. O presente trabalho teve como objetivos determinar a possível presença de infecção por Leishmania sp em cães domésticos residentes em foco endêmico para LTA, no Município de Balneário Camboriú e verificar a existência de correlação entre a resposta imune humoral e celular, presença de lesões sugestivas e positividade no exame parasitológico direto. Métodos: Foram cadastrados 275 animais, os quais foram examinados segundo seus aspectos clínicos, desenvolvimento de hipersensibilidade tardia ao antígeno Immunoleish e respostas sorológicas à reação de imunofluorescência indireta e ao ensaio imunoenzimático. Resultados: Sete animais apresentaram lesões suspeitas, porém não foram encontradas Leishmanias pelo método parasitológico direto. O resultado da sorologia foi de $5,8 \%$ de positividade com a RIFI, $6,2 \%$ com o ELISA e $1,8 \%$ com a prova intradérmica. Somando os cães positivos pelos exames sorológicos e/ou pela prova intradérmica obteve-se um total de 24 positivos, imunoprevalência de 8,7\% para LTA. Conclusões: Há necessidade de mais estudos para avaliar a participação dos cães na cadeia epidemiológica da LTA no Município de Balneário Camboriú.

Palavras-chaves: Diagnóstico. Leishmania. Cães. Santa Catarina.
\end{abstract}

\begin{abstract}
Introduction: The increase in American tegumentary leishmaniasis (ATL) cases in 2005 was due to an outbreak that occurred in the towns of Itapema and Balneário Camboriú. This study aimed to determine the possible presence of infection by Leishmania sp in domestic dogs living in an endemic focus of ATL in the town of Balneário Camboriú and verify the existence of a correlation between the humoral and cellular immune responses, the presence of suggestive lesions and positivity in direct parasitological exams. Methods: A total of 275 dogs were evaluated, examined according to clinic aspects, the development of delayed hypersensitivity to Immunoleish antigens and serological responses to the indirect immunofluorescence reaction and immunoenzymatic assay. Results: Seven dogs presented suspect lesions, but Leishmania was not detected using the direct parasitological method. The serological result was $5.8 \%$ positivity using the IIFR technique, $6.2 \%$ by ELISA and $1.8 \%$ using the intradermal test. The total number of dogs positive for ATL using the serological exams and/or intradermal test was 24, indicating prevalence of $8.7 \%$ for ATL. Conclusions: Further studies are required to evaluate the participation of dogs in the epidemiological chain of ATL in Balneário Camboriú.
\end{abstract}

Key-words: Diagnosis. Leishmania. Dogs. Santa Catarina.

1. Clínica Veterinária TOP DOG, Balneário Camboriú, SC. 2. Centro de Ciências Agroveterinárias, Universidade do Estado de Santa Catarina, Lages, SC. 3. Laboratório de Zoonoses, Escola Nacional de Saúde Pública Sérgio Arouca, Fundação Oswaldo Cruz, Rio de Janeiro, RJ.

Endereço para correspondência: MSc. Afonso Heusser Júnior. Clínica Veterinária TOP DOG. Rua 2550, 549, 88330-390 Balneário Camboriú, SC.

e-mail: heusser@terra.com.br

Received in 17/12/2009

Accepted in 16/09/2010

\section{INTRODUÇÃO}

As leishmanioses são doenças infecciosas de caráter crônico e manifestações clínicas que, segundo Cruz e Coutinho ${ }^{1}$, variam desde a forma cutânea, cutâneo-mucosa, cutânea disseminada, cutânea difusa (leishmaniose tegumentar-LT) até uma forma visceral (leishmaniose visceral-LV), conforme a espécie infectante e a condição imunológica do hospedeiro. São causadas por protozoários patogênicos do gênero Leishmania, classificado na ordem Kinetoplastida, família Trypanosomatidae e que acomete o homem e várias espécies de animais silvestres e domésticos. São transmitidas por insetos dípteros hematófagos pertencentes à subfamília Phlebotominae. No Brasil, os casos de transmissão da leishmaniose tegumentar americana (LTA) estão representados por seis espécies, sendo as mais importantes, sob ponto de vista nosológico humano, Leishmania (Viannia) braziliensis, Leishmania (Leishmania) amazonensis e Leishmania (Viannia) guyanensis ${ }^{2}$.

Em Santa Catarina, a doença em humanos foi constatada, pela primeira vez, nos Municípios de Quilombo e Coronel Freitas ${ }^{3}$. A ocorrência de leishmaniose cutânea e mucocutânea, comidentificação de um novo foco de transmissão da doença, foi verificada no Município de Piçarras ${ }^{4}$. No Município de Balneário Camboriú, as primeiras notificações de casos autóctones de LTA ocorreram em 2005 nas quais foi identificado como agente Leishmania $\left(V\right.$.) braziliensis ${ }^{5}$. No período de 2001 a 2006, foram confirmados casos autóctones nos seguintes Municípios de Santa Catarina: Aurora (2 casos), Balneário Barra do Sul (1), Balneário Camboriú (37), Blumenau (52), Botuverá (4), Camboriú (10), Caxambú do Sul (1), Corupá (4), Florianópolis (1), Guaraciaba (2), Itajaí (2), Itapema (5), Jupiá (1), Massaranduba (2), Piçarras (9), Presidente Nereu, (1) e São Ludgero (1) ${ }^{6}$. Estudos da fauna flebotomínica nas áreas de ocorrência de casos de LTA nos Municípios de Blumenau ${ }^{7}$ e Piçarras ${ }^{8}$ revelaram a presença predominante de Lutzomyia neivai, espécie altamente antropofílica e apontada como provável vetor da doença naquelas localidades 9 . 
Verifica-se a expansão da LTA no estado e a necessidade de atenção e mais estudos sobre a participação de animais domésticos no perfil epidemiológico das respectivas áreas endêmicas. A existência de animais silvestres como fonte natural de infecção, ainda insuficientemente estudada, parece incapaz de explicar a totalidade dos casos humanos, levando a supor que existam outros ciclos, onde o homem e animais domésticos participem ${ }^{10,11}$, o que é agravado pela adaptabilidade de certas espécies vetoras a ambientes antrópicos.

Estudos sobre a participação do cão doméstico em ciclos de transmissão da LTA no Brasil foram intensificados a partir de $1980^{12}$. O primeiro diagnóstico de um cão naturalmente parasitado por espécies do gênero Leishmania, com leishmaniose tegumentar, no Brasil, coube a Pedroso em $1913^{12}$. Autores $^{13}$ consideraram que os achados clínicos, histopatológicos e sorológicos em cães experimentalmente infectados foram similares aos verificados na infecção canina natural, bem como na doença humana. Trabalhos mais recentes têm mostrado ser relativamente comum a presença de cães infectados por Leishmania $(V)$ braziliensis em diferentes focos de LTA. Assim, uma pesquisa realizada em 126 cães de área endêmica no Município de Mariluz (PR) revelou uma soroprevalência de $19 \%{ }^{14}$. No Município de Jussara, noroeste do Paraná, onde já haviam sido detectados três casos de LTA em cães ${ }^{15}$, foi constatado soropositividade em 18,2\% de 132 animais avaliados ${ }^{16}$. No Estado do Rio de Janeiro, vários levantamentos sorológicos em cães foram realizados em municípios endêmicos ${ }^{17-22} \mathrm{com}$ positividade variando entre 3,2\% a 16,7\%. A ocorrência de LTA no Estado do Espírito Santo evidencia a nítida relação entre cães infectados e o surgimento de novos casos humanos, acreditando-se que a doença se mantém como uma provável antropozoonose na região ${ }^{23}$. Em um estudo desenvolvido em duas áreas geograficamente distintas ${ }^{24}$, Solano, na Venezuela e em Mesquita, no Estado do Rio de Janeiro, Brasil, os autores encontraram positividade de $2,9 \%$ e $19,8 \%$, respectivamente. As cepas isoladas em ambas as localidades foram caracterizadas como Leishmania $(V)$ braziliensis. Esses resultados, segundo os autores, fortalecem a idéia de que o cão mantém as características zoonóticas da leishmaniose tegumentar, nos municípios estudados. Positividade de $22,5 \%$ foi constatada em levantamento sorológico realizado em cães de áreas rural e urbana do Município de Uberlândia, Minas Gerais $^{25}$. Posteriormente, no mesmo município ${ }^{26}$, constataram diminuição na prevalência sorológica de cães para a LTA, com valores de $1 \%$ na área rural e de $10,6 \%$, na área urbana, concluindo que esta espécie animal pode representar um importante papel como reservatório da infecção em grandes centros. Estudando aspectos clínicos e epidemiológicos da LTA no Município de Araçuaí, Minas Gerais ${ }^{27}$, encontraram soroprevalência canina de $20,3 \%$ e afirmaram que esses animais seriam os responsáveis pela manutenção do ciclo peridoméstico naquela cidade. Constatação semelhante foi feita no Município de Porto Alegre, Rio Grande do $\mathrm{Sul}^{28}$, em um levantamento sorológico, embora com baixa positividade, 3,5\%, e com ausência de sintomas nos animais.

A presença de cães infectados em áreas endêmicas de LTA tem sido investigada considerando seu papel como reservatório na cadeia de transmissão de Leishmania sp nos ambientes domiciliar e peridomiciliar. Porém, o ciclo de transmissão apresenta características peculiares de cada região endêmica, por isso, nem sempre é possível extrapolar dados de uma localidade para outra, pois as condições fitogeográficas tendem a ser distintas, podendo não haver similaridades entre os fatores bióticos como, a presença da mesma espécie de parasita, reservatórios silvestres e flebotomíneos.
O Estado de Santa Catarina é o único da região Sul onde não há casos registrados de leishmaniose visceral (LV) em humanos ou em cães, assim como nenhum trabalho publicado sobre os reservatórios silvestres e domésticos nos focos de LTA.

Considerando-se a relevância da doença e a falta de dados epidemiológicos referentes à LTA no Estado de Santa Catarina em cães domiciliados, realizou-se o presente estudo, com os objetivos de determinar o percentual de cães imunologicamente reagentes por meio da pesquisa de anticorpos antiLeishmania sp e da resposta celular de hipersensibilidade tardia in vivo, relacionando os resultados obtidos com a pesquisa direta dos parasitos e considerando a presença ou ausência de lesões sugestivas.

\section{MÉTODOS}

O Município de Balneário Camboriú está localizado no litoral de Santa Catarina, latitude $26^{\circ} 59^{\prime} 27^{\prime \prime}$ sul e longitude $48^{\circ} 38^{\prime}$ $06^{\prime \prime}$ oeste. Segundo o censo do Instituto Brasileiro de Geografia e Estatística ${ }^{29}$ a população em 2007 era de 94.344 habitantes. A área estudada pertence ao bairro da Barra, com uma população de 4.219 habitantes ${ }^{30}$, local onde foram notificados no final do ano de 2005 e início de 2006, casos de LTA humana. O levantamento epidemiológico foi realizado no período de janeiro a abril de 2007.

A partir de residências onde foram diagnosticados casos de leishmaniose tegumentar em humanos, foram realizadas visitas as pessoas de moradias, co-habitantes com cães, num raio de $1 \mathrm{~km}$. Inicialmente, era preenchida uma ficha clínico-epidemiológica e laboratorial para cada animal com os seguintes dados: proprietário (nome, endereço e telefone), presença de infecção humana no domicílio, nome do cão, sexo, raça, idade, pelagem, tempo de residência na área; características de comportamento, ou seja, domiciliados, cães com atividade limitada, mantidos nas residências ou semidomiciliados, animais com liberdade de circularem pelo bairro, retornando a residência para se alimentar e dormir, local onde o cão passa a noite, proximidade da residência em relação à floresta, presença de outros animais no peridomicílio e resultado dos exames imunológicos e parasitológicos.

Em seguida, os animais eram imobilizados para o exame clínico, realização do teste intradérmico e a coleta de sangue.

\section{Teste intradérmico}

Foi realizado o inóculo intradérmico de $0,1 \mathrm{~mL}$ do antígeno Imunoleish $^{31}$, na face interna da coxa do membro posterior direito, de cada cão a ser estudado. O local do inóculo foi devidamente dermografado e a leitura realizada após $48 \mathrm{~h}$. Foram consideradas positivas as reações (enduração) de diâmetro igual ou superior a $5 \mathrm{~mm}$, aferidas por meio de um paquímetro.

\section{Diagnóstico parasitológico}

Os cães foram examinados em busca de lesões cutâneas compatíveis com LTA, ou seja, lesões cicatriciais, pápulas ou úlceras arredondadas bem delimitadas. Quando presentes, estas foram escarificadas e o material obtido fixado com metanol em laminas, corado pelo método de Giemsa e examinado ao microscópio óptico (objetiva100X e ocular de 10X) para pesquisa de formas amastigotas.

\section{Diagnóstico sorológico}

Amostras de sangue dos cães foram coletadas por punção da veia jugular externa e acondicionadas em tubos de ensaio sem anticoagulante. Os soros foram aliquotados $(100 \mu \mathrm{L})$, identificados 
e armazenados na temperatura de $-18^{\circ} \mathrm{C}$. As amostras foram analisadas no Departamento de Ciências Biológicas da Escola Nacional de Saúde Pública da Fundação Oswaldo Cruz (DCB-ENSP/FIOCRUZ) por meio das técnicas de reação de imunofluorescência indireta (RIFI) e enzyme linked immunossorbent assay (ELISA), in house. Para a RIFI, foi utilizado como antígeno formas promastigotas integras de Leishmania (V) braziliensis (MCAN/BR/94/MALHADO), com sete dias de crescimento em cultura e, para o ELISA, antígeno parcialmente solúvel obtido por centrifugação a $10.000 \mathrm{~g} / 10 \mathrm{~min}$, de promastigotas rompidas por congelamento e descongelamento seguido de sonicação.

Para a comparação das técnicas de RIFI e ELISA, foram calculadas a sensibilidade e especificidade, valores preditivos positivo e negativo, utilizando-se o teste RIFI como de referência ${ }^{32}$. Foram considerados suspeitos de infecção os cães reagentes a pelo menos uma das técnicas diagnósticas utilizadas (RIFI, ELISA, teste intradérmico).

\section{Análise estatística}

Os dados das variáveis contidas na ficha clínico-epidemiológica e laboratorial foram submetidos à análise pelo teste do qui-quadrado e adotou-se 5\% de nível de significância.

\section{Ética}

O projeto foi submetido e aprovado no Comitê de Ética em Experimentação Animal do Centro de Ciências Agroveterinárias (CETEA/CAV), da Universidade do Estado de Santa CatarinaUDESC, protocolo no $1.25 / 06$.

\section{RESULTADOS}

No bairro da Barra, município de Balneário Camboriú (SC) foram visitadas 178 residências, sendo que em 13 (7,3\%) havia um ou mais casos de LTA em humanos. Foram cadastrados 275 cães, perfazendo a média de 1,5 cães por habitação. Com relação ao sexo dos animais, 166 (60,4\%) eram machos e 109 (39,6\%) fêmeas. Quanto à raça, $197(71,6 \%)$ eram sem raça definida (SRD) e $78(28,4 \%)$ pertenciam a várias raças.

A presença de animais silvestres no peridomicílio foi observada e relatada por moradores de $51(28,6 \%)$ residências, predominando a presença de roedores e marsupiais. Considerando ainda o ambiente domiciliar, observou-se que $76(42,7 \%)$ dos domicílios visitados estavam situados a menos de $50 \mathrm{~m}$ da mata, sendo que $21(11,8 \%)$ deles situavam-se no interior da floresta.

Na Tabela 1, constam os resultados obtidos com a ficha epidemiológica: os animais foram estratificados por idade, sendo que $36(13,1 \%)$ tinham menos de um ano, $171(62,2 \%)$ entre um e quatro e $68(24,7 \%)$ com mais de quatro anos e agrupados de acordo com a atividade: semidomiciliados, que totalizaram 118 (43\%) e os domiciliados 157 (57\%).

Lesões cutâneas sugestivas de LTA (Figura 1) foram identificadas em sete $(2,5 \%)$ animais, sendo dois $(0,7 \%)$ com lesão cicatricial suspeita. As lesões localizavam-se, no pavilhão auricular, três (1\%); focinho, um ( $0,4 \%)$; bolsa escrotal, dois $(0,7 \%)$ e membro posterior, um $(0,4 \%)$. As lesões ulceradas eram únicas e úmidas. Ao exame parasitológico direto, através da escarificação, não foi possível a visualização de formas amastigotas do parasita.

$\mathrm{Na}$ pesquisa sorológica de anticorpos antiLeishmania sp, verificou-se positividade isolada, para RIFI, em três $(1,1 \%)$ amostras, para ELISA, em quatro (1,4\%) e, para ambos os testes, em 13 (4,7\%). Dos cães sorologicamente positivos, apenas dois apresentaram lesão
TABELA 1 - Dados obtidos a partir da ficha epidemiológica para a LTA canina utilizada no estudo realizado, de janeiro a abril de 2007, no Bairro da Barra, em Balneário Camboriú, SC.

\begin{tabular}{|c|c|c|}
\hline Variáveis & $\begin{array}{c}\text { Número } \\
(275)\end{array}$ & $\begin{array}{c}\text { Porcentagem } \\
(\%)\end{array}$ \\
\hline \multicolumn{3}{|l|}{ Idade (anos) } \\
\hline$<1$ & 36 & 13,1 \\
\hline $1-4$ & 171 & 62,2 \\
\hline$>4$ & 68 & 24,7 \\
\hline \multicolumn{3}{|l|}{ Atividade } \\
\hline semidomiciliado & 118 & 42,9 \\
\hline domiciliado & 157 & 57,1 \\
\hline \multicolumn{3}{|l|}{ Infecção humana } \\
\hline $\operatorname{sim}$ & 18 & 6,5 \\
\hline não & 257 & 93,5 \\
\hline \multicolumn{3}{|l|}{ Sinais clínicos* } \\
\hline $\operatorname{sim}$ & 7 & 2,5 \\
\hline não & 268 & 97,5 \\
\hline \multicolumn{3}{|l|}{ Exame sorológico** } \\
\hline positivo & 20 & 7,3 \\
\hline negativo & 255 & 92,7 \\
\hline \multicolumn{3}{|l|}{ Reação intradérmica } \\
\hline positiva & 5 & 1,8 \\
\hline negativa & 270 & 98,2 \\
\hline \multicolumn{3}{|c|}{ Suspeita de infecção pela LTA } \\
\hline $\operatorname{sim}$ & 24 & 8,7 \\
\hline não & 251 & 91,3 \\
\hline
\end{tabular}

suspeita para LTA, sendo um com lesão cutânea localizada na bolsa escrotal e outro com lesão no pavilhão auricular.

Pelo teste intradérmico realizado em todos os 275 cães, verificouse reação inflamatória tardia positiva em apenas cinco $(1,8 \%)$ animais. Destes, apenas dois apresentavam lesões sugestivas para LTA, um com lesão cutânea na face interna do membro posterior e outro, portador de uma cicatriz em bolsa escrotal (Figura 1).

Considerando-se os resultados positivos alcançados em uma das técnicas laboratoriais, intradermorreação, RIFI ou ELISA, obteve-se um total de 24 (8,7\%) animais considerados suspeitos de infecção por LTA. Dentre esses cães, apenas quatro $(16,7 \%)$ apresentavam lesões sugestivas de LTA. Todos eram machos, possuíam idade inferior a quatro anos, exceto um (4,2\%), com idade de 15 anos, residiam a menos de $50 \mathrm{~m}$ da floresta, três $(12,5 \%)$ eram domiciliados e um $(4,2 \%)$ possuía hábitos semidomiciliados, três $(12,5 \%)$ não conviviam com indivíduos com LTA, dois $(8,3 \%)$ foram positivos simultaneamente para RIFI e ELISA e os outros dois (8,3\%) para o teste intradérmico (Tabela 2).

Não houve diferença estatística com relação às idades dos animais e a positividade dos exames sorológicos (RIFI e ELISA). Também não se verificou associação estatística entre positividade sorológica e a presença, ou não, de infecção humana na residência, distância da residência em relação à floresta, bem como atividade dos cães (domiciliados ou semidomiciliados). A não diferença estatística nas variáveis apontadas possivelmente deve-se ao pequeno número de casos positivos (Tabela 3). 


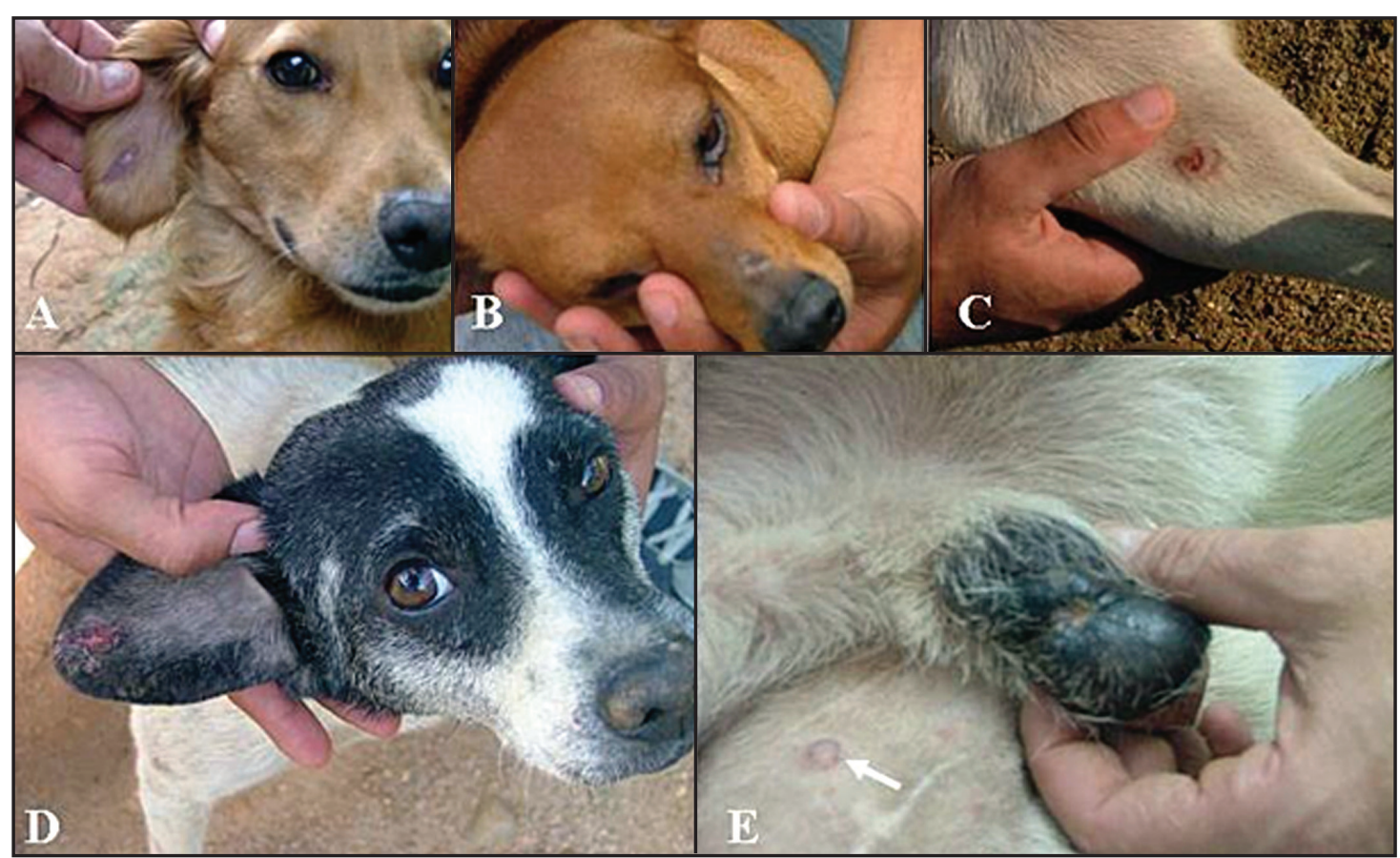

FIGURA 1 - Lesões sugestivas de LTA em caninos do município de Balneário Camboriú, SC. A) lesão cicatricial no pavilhão auricular; B) lesão ulcerada no focinho; C) lesão ulcerada na face interna do membro posterior; D) lesão ulcerada no pavilhão auricular; E) lesão cicatricial em bolsa escrotal com reação intradérmica positiva (seta).

TABELA 2 - Distribuição dos resultados laboratoriais frente ao sexo, idade, atividade, proximidade da floresta e presença de caso humano de LTAna residência, janeiro a abril de 2007, na Barra, Município de Balneário Camboriú, SC.

\begin{tabular}{|c|c|c|c|c|c|c|c|c|c|}
\hline \multicolumn{3}{|c|}{ Identificação } & \multirow[b]{2}{*}{$\mathrm{PF}(\mathrm{m})$} & \multirow[b]{2}{*}{ Atividade } & \multirow[b]{2}{*}{$\mathrm{IH}$} & \multirow[b]{2}{*}{ IDR } & \multirow[b]{2}{*}{ RIFI } & \multirow[b]{2}{*}{ ELISA } & \multirow[b]{2}{*}{ LS } \\
\hline$n^{0}$ & sexo & idade & & & & & & & \\
\hline 1 & M & $2 \mathrm{a}$ & 50 & $\mathrm{D}$ & não & - & + & + & $\mathrm{a}$ \\
\hline 2 & M & $2 a$ & 50 & $S$ & não & - & + & - & $\mathrm{a}$ \\
\hline 3 & M & $2 a$ & 50 & $\mathrm{D}$ & sim & + & + & + & a \\
\hline 4 & M & $3 a$ & 50 & $\mathrm{D}$ & sim & - & + & + & a \\
\hline 5 & M & $15 a$ & 50 & $\mathrm{D}$ & não & - & + & + & $\mathrm{p}$ \\
\hline 6 & M & $3 a$ & 50 & $S$ & não & - & + & - & $\mathrm{a}$ \\
\hline 7 & $\mathrm{~F}$ & $7 a$ & 100 & $\mathrm{D}$ & não & - & + & + & a \\
\hline 8 & M & $6 \mathrm{~m}$ & 100 & $\mathrm{D}$ & não & - & + & - & a \\
\hline 9 & $\mathrm{~F}$ & $6 a$ & $>500$ & $\mathrm{D}$ & não & - & + & + & $\mathrm{a}$ \\
\hline 10 & $\mathrm{~F}$ & $4 a$ & 50 & S & não & - & - & + & $\mathrm{a}$ \\
\hline 11 & M & $8 \mathrm{~m}$ & 50 & $\mathrm{D}$ & não & + & - & - & $\mathrm{p}$ \\
\hline 12 & $\mathrm{~F}$ & $4 a$ & NM & $\mathrm{D}$ & $\operatorname{sim}$ & - & + & + & a \\
\hline 13 & M & $2 a$ & NM & S & $\operatorname{sim}$ & - & + & + & a \\
\hline 14 & M & $3 a$ & NM & $S$ & $\operatorname{sim}$ & - & + & + & a \\
\hline 15 & M & $5 a$ & $\mathrm{NM}$ & $\mathrm{D}$ & não & + & - & - & a \\
\hline 16 & $\mathrm{~F}$ & 1a & NM & S & não & - & + & + & $\mathrm{a}$ \\
\hline 17 & $\mathrm{~F}$ & $5 a$ & 50 & D & não & - & + & + & $\mathrm{a}$ \\
\hline 18 & $\mathrm{M}$ & $9 \mathrm{~m}$ & 50 & S & não & - & + & + & a \\
\hline 19 & M & $3 a$ & 50 & $S$ & não & - & + & + & $\mathrm{p}$ \\
\hline 20 & $\mathrm{M}$ & 1a & 50 & $\mathrm{D}$ & não & - & - & + & $\mathrm{a}$ \\
\hline 21 & $\mathrm{M}$ & $3 a$ & 100 & $S$ & não & + & - & - & a \\
\hline 22 & $\mathrm{M}$ & $4 a$ & 50 & S & $\operatorname{sim}$ & + & - & - & $\mathrm{p}$ \\
\hline 23 & $\mathrm{M}$ & $2 a$ & NM & $\mathrm{S}$ & não & - & - & + & a \\
\hline 24 & $\mathrm{~F}$ & $3 a$ & NM & $S$ & não & - & - & + & $\mathrm{a}$ \\
\hline
\end{tabular}

PF: proximidade da floresta, NM: na mata, D: domiciliado, S: semidomiciliado, $\mathrm{IH}$ : infecção humana na residência, IDR: intradermorreação, +: positivo, -: negativo, RIFI: reação de imunofluorescência indireta, ELISA: enzyme linked immunossorbent assay, LS: lesão sugestiva, a: ausente, p: presente, M: masculino, F: feminino.
TABELA 3 - Análise estatística dos resultados obtidos pelos testes de RIFI e ELISA na detecção de anticorpos antiLeishmania sp em cães e as variáveis do ambiente, atividade e presença de infecção humana de LTA na residência, janeiro a abril de 2007, em Balneário Camboriú, SC.

\begin{tabular}{|c|c|c|c|c|c|c|}
\hline \multirow[b]{2}{*}{ Variáveis } & \multirow{2}{*}{$\frac{\text { ELISA }}{\text { positivos/total }}$} & \multirow[b]{2}{*}{$\chi^{2}$} & \multirow[b]{2}{*}{$\mathrm{P}$} & \multicolumn{2}{|l|}{ RIFI } & \multirow[b]{2}{*}{$\mathrm{P}$} \\
\hline & & & & positivos/total & $\chi^{2}$ & \\
\hline Idade (anos) & & 2,37 & 0,3046 & & 0,52 & 0,7710 \\
\hline$<1$ & $1 / 3$ & & & $2 / 3$ & & \\
\hline $1-4$ & $12 / 16$ & & & $10 / 16$ & & \\
\hline$>4$ & $4 / 5$ & & & $4 / 5$ & & \\
\hline Sexo & & 2,19 & 0,1389 & & 0,10 & 0,7499 \\
\hline macho & $10 / 17$ & & & $11 / 17$ & & \\
\hline fêmea & $7 / 7$ & & & $5 / 7$ & & \\
\hline Atividade & & 0,20 & 0,6547 & & 0,75 & 0,3864 \\
\hline semidomiciliado & $8 / 12$ & & & $7 / 12$ & & \\
\hline domiciliado & $9 / 12$ & & & $9 / 12$ & & \\
\hline Onde passa à noite & & 0,43 & 0,5080 & & 0,51 & 0,4747 \\
\hline dentro de casa & $1 / 1$ & & & $1 / 1$ & & \\
\hline fora de casa & $16 / 23$ & & & $5 / 23$ & & \\
\hline Distância da mata (m) & & 2,61 & 0,2702 & & 0,51 & 0,7725 \\
\hline$\leq 50$ & $15 / 20$ & & & $13 / 20$ & & \\
\hline $51-200$ & $1 / 3$ & & & $2 / 3$ & & \\
\hline$>200$ & $1 / 1$ & & & $1 / 1$ & & \\
\hline Presença de animais & & 0,89 & 0,3454 & & 0,89 & 0,3454 \\
\hline roedores & $1 / 2$ & & & $1 / 2$ & & \\
\hline roedores e marsupiai & ais $5 / 6$ & & & $5 / 6$ & & \\
\hline Proprietário & & 0,60 & 0,4385 & & 1,00 & 0,3173 \\
\hline com LTA & $5 / 6$ & & & $5 / 6$ & & \\
\hline sem LTA & $12 / 18$ & & & $11 / 18$ & & \\
\hline
\end{tabular}




\section{DISCUSSÃo}

As lesões cutâneas únicas e úmidas observadas neste trabalho eram compatíveis com as descritas por alguns autores ${ }^{33}$, causadas por parasitos do complexo Leishmania braziliensis. Em um estudo ${ }^{34}$ realizado em área endêmica de LTA humana, localizada no Norte do Paraná foi constatado a presença de lesão tegumentar em 14 (20,9\%) cães, dos quais apenas três $(21,4 \%)$ apresentavam, concomitantemente, RIFI e pesquisa direta de parasito positivas, enquanto nove $(81,8 \%)$ possuíam apenas a RIFI positiva, sugerindo que apesar de não ter sido encontrados parasitas nas lesões, esses animais poderiam estar infectados por Leishmania sp. A baixa positividade da pesquisa direta do parasito pode ser em consequência da escassez de parasitas nas lesões de cães ${ }^{35}$. Desta forma, o diagnóstico da LTA canina deve levar em consideração a eventual presença de quadros dermatológicos incomuns, a dificuldade de encontro do parasito e a possível variação na resposta imune individual. Além disso, apesar de ser simples e de baixo custo, o exame direto para detecção do parasita possui uma sensibilidade inversamente proporcional ao tempo de evolução da lesão ${ }^{36-38}$. Em uma região endêmica do Espírito Santo, foram examinados 186 cães, destes 46 apresentavam lesões suspeitas, sendo 31 parasitados por leishmânias ${ }^{23}$. Em área endêmica de Minas Gerais, foram investigados 355 cães e constatado 27 com lesões ou manchas hipocrômicas e em apenas seis o esfregaço foi positivo ${ }^{39}$. Para esses autores, o esfregaço não constitui processo ideal para diagnóstico de leishmaniose tegumentar, devido ao baixo número de parasitas presentes nas lesões, o que talvez justifique os resultados negativos encontrados neste trabalho, quando foram observados sete $(2,5 \%)$ animais com lesões suspeitas, dos quais quatro eram positivos por meio das técnicas imunológicas empregadas (intradermorreação e/ou sorologia). Para dirimir equívocos ${ }^{18}$, sugeriram que cães com lesões sugestivas de LTA, provenientes de áreas endêmicas, sejam acompanhados periodicamente com o objetivo de confirmar o diagnóstico.

A RIFI é a técnica de referência para o estudo de soroprevalência da LTA canina no Brasil devido a sua maior especificidade e títulos significativos de anticorpos evidenciados em cães portadores ou não de lesões. A não reatividade do teste de RIFI diante da reatividade no ELISA em algumas amostras caninas, encontrada nesta pesquisa, pode ser explicada pela maior sensibilidade da reação isoenzimática. No entanto, quando aplicado em estudos epidemiológicos em área de LTA, a especificidade do ELISA pode tornar-se baixa, devido à ocorrência de reações inespecíficas ${ }^{19}$

A taxa de 5,8\% para RIFI obtida neste estudo pode ser considerada baixa quando comparada com outras pesquisas realizadas em diferentes regiões do Brasil, cujas taxas de soropositividade variaram de $3,2 \%$ a $22,5 \%$. O percentual foi menor que os obtidos in house, com Leishmania $(V)$ braziliensis e com o mesmo ponto de corte $(\geq 40)^{16,14}$. Porém, o resultado evidencia a importância dos cães como possíveis reservatórios e a necessidade de mais estudos para avaliar a participação destes no ciclo biológico da LTA no município.

Os resultados da pesquisa sorológica devem-se, provavelmente, ao período imunológico em que se encontrava a infecção canina na área estudada, evidenciando um processo recente de transmissão. Essa hipótese é reforçada quando se observa que $21 \%$ dos animais positivos possuem até um ano de idade, assim como o perfil epidemiológico evidenciado, com uma maior proporção de sorologia positiva $(7,3 \%)$ sobre o teste cutâneo positivo $(1,8 \%)$. Os exames sorológicos podem positivar em animais com lesões ativas, com infecções subclínicas ou podem indicar infecções recentes (sem lesões ${ }^{40}$, como é o caso sugerido neste estudo, uma vez que a presença de lesão sugestiva para LTA ocorreu em apenas 2,5\% dos animais. A vantagem da utilização do antígeno intradérmico sobre a sorologia é a sua facilidade de execução no campo, oferecendo um diagnóstico rápido (em $48 \mathrm{~h}$ ), que poderá ser executado durante a aplicação do teste de Montenegro nos inquéritos humanos ${ }^{41}$. A inexistência de cães com lesões suspeitas em áreas endêmicas de LTA humana não significa que a doença canina não esteja ativa ${ }^{25}$. Os mesmos autores consideraram a positividade da RIFI como indicador de infecção canina. A presença de cães sem lesão e com sorologia positiva em áreas endêmicas também foi reportada por outros autores ${ }^{18,22,31,33}$.

A utilização de mais de uma técnica laboratorial para o diagnóstico da LTA canina, com diferentes antígenos e metodologias, é recomendável, quando o padrão ouro (pesquisa direta de parasitas) muitas vezes apresenta baixa prevalência.

O maior percentual entre os animais positivos $(83,3 \%)$ em residências, no trecho de até $50 \mathrm{~m}$ de distância da floresta deve-se, provavelmente, as características ecológicas do local. A vegetação, ainda nativa, é abundante e a diversidade de animais sinantrópicos e silvestres propiciam excelentes condições bióticas à presença da fauna flebotomínea e consequentemente à disseminação do agente etiológico desta doença. Pesquisa realizada com 389 cães errantes capturados próximos as matas residuais do município de São Paulo, mostrou pela RIFI, 19,3\% de sororeagentes ${ }^{42}$.

Outra informação considerada importante é o fato de que, neste estudo, apenas cinco cães sorologicamente positivos eram domiciliados junto a caso humano de LTA. Devido à proximidade das residências com a mata nativa, tanto os cães quanto as pessoas poderiam estar se infectando a partir da picada do inseto vetor com formas obtidas em reservatórios, que poderiam ser, ao menos por enquanto, apenas animais silvestres. Os fatores relacionados com a epidemiologia da LTA variam entre regiões endêmicas e pode ser que em certas regiões o cão não desempenhe papel significativo, enquanto que em outras, pode atuar como reservatório secundário, ou ainda, como amplificador da infecção, mantendo a parasitose nas áreas de peri e intradomicílio ${ }^{43-45}$.

A imunoprevalência humoral e celular de leishmaniose tegumentar canina no Município de Balneário Camboriú, Santa Catarina, foi de $8,7 \%$;

Não foi observada associação entre positividade e presença de humanos infectados nas residências investigadas;

Há necessidade de mais estudos para avaliar a participação dos cães na cadeia epidemiológica da LTA no Município de Balneário Camboriú.

\section{CONFLITO DE INTERESSE}

Os autores declaram não haver nenhum tipo de conflito de interesse no desenvolvimento do estudo.

\section{REFERÊNCIAS}

1. Cruz AM, Coutinho RBA. Leishmaniose Tegumentar Americana. In: Batista RS Igreja RP, Gomes AD, Huggins DW, editores. Medicina Tropical: abordagem atual das doenças infecciosas e parasitárias. Rio de Janeiro: Cultura Médica; 2001. p.131-140. 
2. Cupolillo E, Grimaldi Jr G, Momen H. A general classification of new world Leishmania using numerican zymotaxonomy. AmJ Trop MedHyg 1994; 50:296-311.

3. São Thiago PT, Guida U. Leishmaniose tegumentar no oeste do Estado de Santa Catarina, Brasil. Rev Soc Bras Med Trop 1990; 23:201-203.

4. Lima Filho JHC, Steindel M. Aspectos clínicos e epidemiológicos da leishmaniose cutânea no Estado de Santa Catarina. Arq Catarinenses Med 1998; 27:25-31.

5. Eger-Mangrich I, Moraes MH, Scholl D, Rosseto AL, Mora JM, Masukawa I, et al. Expansão do foco de Leishmaniose Tegumentar Americana no estado de Santa Catarina. In: XIX Congresso Brasileiro de Parasitologia, 2005, Porto Alegre. Rev Patol Trop 2005; 34 (supl. esp): CD- ROM.

6. Ministério da Saúde. Sistema de Informação de Agravos de Notificação. Ministério da Saúde; Secretaria de Vigilância em Saúde. Brasília; 2004. Acesso em 29 de março de 2007. Disponível em: <http://dtr2004.saude.gov.br/sinanweb/ tabnet?sinan/lta/bases/ltabr.def $>$

7. Secretaria de Estado da Saúde. Levantamento de fauna flebotomínica relacionado ao surto de Leishmaniose Tegumentar Americana em Blumenau. Divisão de Vigilância Epidemiológica. Florianópolis; 2006.

8. Marcondes CB, Conceição BEM, Portes MGT, Simão BP. Flebotomíneos num foco de leishmaniose tegumentar na região leste do Estado de Santa Catarina: resultados preliminares (Diptera: Psychodidae). Rev Soc Bras Med Trop 2005 ; 38:353-355

9. Casanova C, Costa AIP, Natal D. Dispersal parttern of the sand fly Lutzomyia neivai (Diptera: Psychodidae) in a cutaneous leishmaniasis endemic rural area in southeastern Brazil. Mem Inst Oswaldo Cruz 2005; 100:719-724.

10. Thomaz-Soccol V. Les Leishmania du Nouveau Monde. Analyse enzymatique. Démarche progressive phénétique-cladistique. Relations phylogénétiques avec les Leishmania de l'Ancien Monde. [These Doctorat Parasitologie]. [Paris]: Faculté de Médicine Montpellier; 1993.

11. Marzochi MCA, Schubach AO, Marzochi KBF. Leishmaniose Tegumentar Ameriacana. In: Cimerman B, Cimerman S editores. Parasitologia Humana: Fundamentos Gerais. 2a ed. São Paulo: Atheneu; 2002. p.39-64.

12. Barbosa GMS. Aspectos epidemiológicos da Leishmaniose Tegumentar Americana em cães, no Município de Paraty, no litoral extremo sul fluminense. [Dissertação Mestrado em Parasitologia Veterinária]. [Rio de Janeiro]. Universidade Federal Rural do Rio de Janeiro; 1997.

13. Pirmez C, Marzochi MCA, Coutinho SG. Experimental canine mucocutaneous leishmaniosis (Leishmania braziliensis braziliensis). Mem Inst Oswaldo Cruz 1988; 83:143-151.

14. Lonardoni MVC, Silveira TGV, Alves WA, Maia-Elkhoury ANS, Membrive UA MembriveNA, etal.Leishmaniose TegumentarAmericanahumana e canina no Município de Mariluz, Estado do Paraná, Brasil. Cad Saude Publica 2006; 22: 2713-2716.

15. Lonardoni MVC, Teodoro U, Arraes SMAA, Silveira TGV, Bertolini DA, Ishikawa EAY, et al. Nota sobre leishmaniose canina no noroeste do Estado do Paraná, sul do Brasil. Rev Saude Publica 1993; 27:378.

16. Silveira TGV, Teodoro U,Lonardoni MVC, Toledo MJO, BertoliniDA, Arraes SMAA et al. Investigação sorológica em cães de área endêmica de leishmaniose tegumentar no Estado do Paraná, sul do Brasil. Cad Saude Publica 1996; 12:89-93.

17. Barbosa GMS, Marzochi MCA, Massard CL, Ginelza OS, Confort EM. Aspectos epidemiológicos da Leishmaniose Tegumentar Americana em cães, no Município de Paraty, Estado do Rio de Janeiro, Brasil. Cad Saude Publica 1999; 15: 641-646.

18. Madeira MF, Serra CMB, Uchôa CMA, Duarte R, Cruz DAM, Perdomo CC. Leishmaniose canina: avaliação sorológica de 310 cães na região de Itaipu, Rio de Janeiro. Cad Saude Publica 2000; 16:568.

19. Uchoa CMA, Serra CMB, Duarte R, Magalhães CM, Silva RM, Theophilo F, et al. Aspectos epidemiológicos da leishmaniose tegumentar Americana canina em Maricá, Rio de Janeiro, Brasil. Rev Soc Bras Med Trop 2001; 34:563-568.

20. Madeira MF, Uchoa CMA, Leal CA, Silva RMM, Duarte R, Magalhães CM, et al. Leishmania (Viannia) braziliensis em cães naturalmente infectados. Rev Soc Bras Med Trop 2003; 36:551-555.

21. Serra CMB, Leal CA, Figueiredo F, Schubach TM, Duarte R, Uchoa CMA et al. Leishmaniose tegumentar canina em Morada das Águias (Serra da Tiririca), Maricá, Rio de Janeiro, Brasil. Cad Saude Publica 2003; 19:1877-1880.

22. Santos GPL, Sanavria A, Marzochi MCA, Santos EGOB, Silva VL, Pacheco RS, et al Prevalência da infecção canina em áreas endêmicas de leishmaniose tegumentar Americana do Município de Paracambi, Estado do Rio de Janeiro, no período entre 1992 e 1993. Rev Soc Bras Med Trop 2005; 38:161-166.

23. Falqueto A, Coura JR, Barros GC, Grimaldi Filho G, Sessa PA, Carias VRD, et al. Participation of the dog in the cicle of transmission of cutaneous leishmaniasis in the Municipality of Viana, State of Espírito Santo, Brazil. Mem Inst Oswaldo Cruz 1986; 81:155-163.
24. Aguilar CM, Rangel EF, Garcia L, Fernandez E, Momen H, Grimaldi Filho G, et al. Zoonotic cutaneous leishmaniasis due to Leishmania (V.) braziliensis associated with domestic animals in Venezuela and Brazil. Mem Inst Oswaldo Cruz 1989; 84:19-28.

25. Cardoso SRA, Machado MI, Costa-Cruz JM, Gonçalves MRF, Stutz WH Leishmaniose tegumentar canina no Município de Uberlândia, Minas Gerais: Diagnóstico clínico e sorológico de cães naturalmente infectados. Rev Centro Cienc Biomed Univ Fed Uberlândia 1989; 5:14-21.

26. Maywald PG, Machado MI, Cruz MC, Oliveira MG, Pires MRFG. Leishmaniose tegumentar canina: inquérito soroepidemiológico em áreas rural e urbana no Município de Uberlândia, Minas Gerais. Braz J Vet Res Anim Sci 1993; 30:25-29.

27. Gontijo CMF, Silva ES, Pacheco RS, Dias ES, Oliveira FS, Michalsky EM, et al Epidemiologia molecular da leishmaniose tegumentar no Município de Araçuaí, Minas Gerais, Brasil. Soc Ibero-Am Inf Cient 2005. [Acesso nov. 2005] Disponível em: http://www.siicsalud.com/des043/05623013.htm/.

28. Jesus JR, Araujo FAP, Spalding S, Tiecher F. Avaliação sorológica de anticorpos para Leishmania spp. na população canina em região de foco de leishmaniose tegumentar Americana na Lomba do Pinheiro, Porto Alegre, Rio Grande do Sul, Brasil. Parasitol Latinom 2006; 61:121-125.

29. Instituto Brasileiro de Geografia e Estatística. Censo 2007. Brasília; 2007. [Acesso jul 2007]. Disponível em http://www.ibge.gov.br/home/estatistica/populacao/ contagem2007/popmunic2007layoutTCU14112007.pdf/.

30. Instituto Brasileiro de Geografia e Estatística. Censo 2000. Brasília; 2000. Acesso em 12 de dezembro de 2006. Disponível em <http://www.ibge.gov.br/censo>

31. MarzochiMCA,BarbosaSantosEG. Evaluation of skin test on the caninemucocutaneous leishmaniasis diagnosis. Mem Inst Oswaldo Cruz 1988; 83: 391-392.

32. World Healt Organization. Leishmaniasis. Acesso em 06 de novembro de 2005 Disponível em: <http://www.who.int/tdr/diseases/leish/diseaseinfo.htm>.

33. Pirmez C, Coutinho SG, Marzochi MC, Nunes MP, Grimaldi G. Canine American cutaneous leishmaniasis: a clinical and immunological study in dogs naturally infected with $L$. braziliensis braziliensis in a endemic area of Rio de Janeiro, Brazil. Am J Trop Med Hyg 1988; 38:52-58.

34. Zanzarini PD, Santos DR, Santos AR, Oliveira O, Poiani LP, Lonardoni MVC, et al. Leishmaniose tegumentar Americana canina em municípios do norte do Estado do Paraná, Brasil. Cad Saude Publica 2005; 21:1957-1961.

35. Marco JD, Padilla AM, Diosque P, Fernández MM, Malchiodi EL, Basombrío MA et al. Force of infection and evolution of lesions of canine tegumentary leishmaniasis in northwestern Argentina. Mem Inst Oswaldo Cruz 2001; 96:649-652.

36. Belli A, Rodriguez B, Aviles H, Harris E. Simplified polymerase chain reaction detection of new world Leishmania in clinical specimens of cutaneous leishmaniasis. Am J Med Hyg 1998; 58:102-109.

37. Medeiros ACR, Rodrigues SS, Roselino AMF. Comparison of the specificity of PCR and the histopatological detection of leishmania for diagnosis of American cutaneous leishmaniasis. Braz J Med Biol Res 2002; 35:421-424.

38. Motazedian H, Karamian M, Noyes HA, Ardehali S. DNA extraction and amplification of Leishmania from archieved, Giemsa-stained slides, for the diagnosis of cutaneous leishmaniasis by PCR. Ann Trop Med Parasitol 2002; 96:31-34

39. Dias M, Mayrink W, Deane LM, Costa CA, Magalhães PA, Melo MN, et al. Epidemiologia da Leishmaniose Tegumentar Americana: estudo de reservatórios em área endêmica no Estado de Minas Gerais. Rev Inst Med Trop São Paulo 1977; 19:403-410.

40. Marzochi MCA, Coutinho SG, Sabroza PC, Souza WJ. Reação de imunofluorescência indireta e intradermorreação para leishmaniose tegumentar Americana em moradores de Jacarepaguá (Rio de Janeiro). Rev Inst Med Trop São Paulo 1980; 22:149-155.

41. SantosEGB.Aleishmaniose tegumentar de animais domésticos. Perspectivas e desafios relacionados ao diagnóstico e ao controle. [Tese Doutorado em Biologia Parasitária], [Rio de Janeiro] Instituto Oswaldo Cruz, Fundação Oswaldo Cruz; 1997.

42. Iversson LB, Camargo ME, Villanova A, Reichmann MLAB, Andrade EA, Tolezano JE. Inquérito sorológico para pesquisa de leishmaniose visceral em população canina urbana do município de São Paulo, Brasil (1979-1982). Rev Inst Med Trop São Paulo 1983; 25:310-317.

43. Reithinger R, Davies CR. Is the domestic dog (Canis familiaris) a reservoir host of American cutaneous leishmaniasis? A critical review of the current evidence. Am J Trop Med Hyg 1999; 61:530-541.

44. Cunha JCL, Lima JWO, Pompeu MML. Transmissão domiciliar de leishmaniose tegumentar e associação entre leishmaniose humana e canina, durante uma epidemia na Serra de Baturité, no estado de Ceará, Brasil. Rev Bras Epidemiol 2006; 9: 425-435.

45. Sabroza PC. O domicílio como fator de risco na leishmaniose tegumentar americana. [Tese Mestrado em Saúde Pública].[Rio de Janeiro] Escola Nacional de Saúde Pública, Fundação Oswaldo Cruz; 1983. 